\title{
BMJ Open Discrimination as a predictor of poor mental health among LGBTQ+ people during the COVID-19 pandemic: cross- sectional analysis of the online Queerantine study
}

Dylan Kneale (1) , ${ }^{1}$ Laia Bécares (1) ${ }^{2}$

To cite: Kneale D, Bécares L. Discrimination as a predictor of poor mental health among LGBTQ+ people during the COVID-19 pandemic: crosssectional analysis of the online Queerantine study. BMJ Open 2021;11:e049405. doi:10.1136/ bmjopen-2021-049405

- Prepublication history and additional supplemental material for this paper are available online. To view these files, please visit the journal online. To view these files, please visit the journal online (http://dx.doi. org/10.1136/bmjopen-2021049405).

DK and LB are joint first authors.

Received 23 January 2021 Accepted 27 May 2021

Check for updates

(C) Author(s) (or their employer(s)) 2021. Re-use permitted under CC BY-NC. No commercial re-use. See rights and permissions. Published by BMJ.

${ }^{1}$ EPPI-Centre, UCL Social Research Institute, University College London, London, UK

${ }^{2}$ Social Work and Social Care, University of Sussex, Falmer, UK

Correspondence to

Dr Dylan Kneale;

D.Kneale@ucl.ac.uk

\section{ABSTRACT}

Objectives To assess the mental health and experiences of discrimination among lesbian, gay, bisexual, transgender, queer (LGBTQ) people at the start of the COVID-19 pandemic.

Design Data come from a cross-sectional online survey targeted at LGBTQ+ people, which collected data on mental health, experiences of discrimination and a number of other pandemic-related experiences. To examine the association between sexual orientation and gender and mental health and experiences of discrimination, we conducted regression analyses that adjusted for a range of sociodemographic variables.

Setting A web-based survey was used to collect data between the end of April and mid July 2020.

Participants An analytical sample of 310 LGBTQ+ respondents aged 18 and above.

Main outcome measures We assessed mental health with the 4-item Perceived Stress Scale and with the 10item Center for Epidemiological Studies Depression scale (CES-D-10). We asked respondents about discriminatory experiences because of their LGBTQ+ identity during the coronavirus pandemic.

Results Perceived stress scores among our LGBTQ+ sample were high (mean: 7.67; SD: 3.22). Based on a score of 10 or more on the CES-D-10, the majority of participants had high levels of depressive symptoms (72\%). Around one-in-six respondents reported some form of discrimination since the start of the pandemic because they were LGBTQ+ $(16.7 \%)$. The average score for perceived stress increased by 1.44 points $(95 \% \mathrm{Cl}$ 0.517 to 2.354 ) for respondents who had experienced discrimination versus those who had not. Similarly, the odds of exhibiting significant depressive symptomology increased threefold among those who had experienced discrimination compared with those who had not (OR: $3.251 ; 95 \%$ Cl 1.168 to 9.052 ).

Conclusions The LGBTQ+ community exhibited high levels of depression, stress and experienced discrimination during the coronavirus pandemic. High levels of poor mental health were partially explained by experiences of discrimination, which had a large, consistent and pernicious impact on mental health.
Strengths and limitations of this study

- This study uses tools that have been validated among diverse populations to identify high levels of perceived stress and depressive symptoms among lesbian, gay, bisexual, transgender, queer (LGBTQ)+ people.

- An online convenience sample was deemed appropriate for a number of reasons including the inherent risk of transmission of COVID-19 with methods involving physical contact and to better include respondents who were sheltering or shielding in households where their LGBTQ+ status was concealed.

- An online convenience sample can introduce issues around representativeness and the possibility that those with greater mental health issues selfselected into the survey.

- Due to relatively small sample sizes, we have not been able to fully examine the diversity of the LGBTQ+ community.

- Designing a survey that captured LGBTQ+ specific experiences allowed us to identify that sexualitybased and gender-based discrimination experienced during the pandemic is an important predictor of mental health issues.

\section{INTRODUCTION}

The coronavirus pandemic has exposed and magnified existent societal and health inequities operating across multiple and intersecting systems of oppression. ${ }^{12}$ Given documented stark health and socioeconomic inequalities across social locations related to sexuality, and gender expression and identity, ${ }^{3}$ the coronavirus disease (COVID-19) and subsequent social and economic implications could be expected to have disproportionate impacts on lesbian, gay, bisexual, transgender and queer people (LGBTQ+, the 'plus' including those who identify as nonheterosexual and/or noncisgender in another way). 
Higher levels of pre-existing health conditions compared with cisgender and heterosexual populations may place the LGBTQ+ community at additional risk of adverse prognosis if diagnosed with COVID-19. This includes long-term chronic illness and higher rates of smoking and asthma among LGBTQ+ people $^{4-7}$; higher rates of obesity and alcohol consumption among lesbian, bisexual and queer women ${ }^{7-9}$ and increased likelihood of being immunocompromised (eg, HIV+ with a low CD4 cell count or with untreated HIV) among gay men and transgender people. ${ }^{10}$ In addition, the impacts of social distancing and lockdown may be felt acutely by LGBTQ+ people, who were at greater risk of poorer mental health prior to the pandemic including higher risks of suicide attempts and suicidal ideation, higher levels of common mental disorders and lower levels of mental well-being. ${ }^{11-13}$ For example, studies using the 4-item Perceived Stress Scale (PSS-4), a measure used in the present study (see the Methods section), have found mean values have ranged between 6.75 and 7.43 for US college students who identified as 'homosexual' and bisexual, respectively, compared with 6.09 among heterosexual students. ${ }^{14}$ Similarly, studies examining depression using the 10-item Center for Epidemiological Studies Depression Scale (CES-D-10), a measure of depressive symptomatology used in the present study (see the Methods section), have found that the proportion reporting substantial depressive symptomology among African American LGB young people to stand at roughly double that of heterosexual young people in the southern USA $(56.1 \%$ vs $28.4 \%){ }^{15}$ Comparative data on LGBTQ+experiences during the pandemic are rare, although in the UK general population, the average stress score (using the PSS-4 scale) was estimated to be $6 \cdot 48$ (SD: 3.3), ${ }^{16}$ above a 6-point threshold used to indicate 'high' levels of stress elsewhere. ${ }^{17}$ Estimates within the general (US) population during the COVID-19 pandemic have suggested that up to a third of people may be experiencing substantial depressive symptomology (using the CES-D-10 scale).$^{18}$

Within the heterogeneous LGBTQ+ umbrellaterm, individual groups may be positioned at a distinct disadvantage. Transgender and gender-diverse (TGGD) individuals have a gender that differs from the culturally bound gender associated with one's assigned birth. ${ }^{19}$ TGGD people are known to experience higher rates of adverse mental health compared with cisgender individuals (people whose gender matches their sex assigned at birth), particularly anxiety, depression and suicidality. ${ }^{5620}$

Despite the accumulation of evidence indicating poorer health among LGBTQ+ people predating the pandemic, there is a dearth of information on whether the hypothesised additional risks outlined above have actually materialised in poorer outcomes among LGBTQ+ people during the COVID-19 pandemic. Indicative evidence suggests that some LGBTQ+ groups may exhibit higher levels of depression and stress during the COVID-19 pandemic, ${ }^{21}$ and other studies suggest that mental health among LGBTQ+ peoplemay have deteriorated during the pandemic compared with prepandemic levels. ${ }^{22}$ However, while some studies indicate that LGBTQ+ people may be more susceptible to stress and depression during the COVID-19 pandemic, this has been largely attributed to existing inequalities in mental health status, with differences attenuating once prepandemic levels of mental health are accounted for. ${ }^{21}$ In other words, although absolute differences in mental health status may be observed, there are few differences between the way in which LGBTQ+ and cisgender-heterosexual people's mental health changed during the pandemic. ${ }^{23}$ The findings from these studies are a cause of concern in of themselves, given that the lockdown entailed a separation from social networks and formal support that could help people in managing mental health issues. However, these studies, which drew on samples of both LGBTQ+ and cisgenderheterosexual respondents, did not account for other risk factors for mental health that may have continued and intensified in potency during the pandemic and resulting lockdown for LGBTQ+ people. Mental health inequalities during and predating the pandemic are a product of complex processes of discrimination and exclusion, ${ }^{24} 25$ and examinations of LGBTQ+ mental health that do not examine these processes may provide an incomplete understanding of how LGBTQ+ people have fared during the pandemic.

Certainly, LGBTQ+ people face stressors during the pandemic that are not shared with heterosexual and cisgender people, including spending periods of 'lockdown' in households that are not affirming or supportive of their sexual orientation or gender identity or expression, ${ }^{26}$ being separated from social networks that are supportive and affirming to their identity ${ }^{27} 28$ and interruptions to accessing gender affirming care among transgender and gender nonbinary people. ${ }^{29} 30$ Theoretical frameworks including the minority stress model suggest that stark health inequalities are the result of distal and proximal stressors caused by living within a homophobic, heterosexist, transphobic culture; these inequalities reflect cumulative experiences of discrimination, harassment, victimisation, expectations of rejection and internalised transphobia and homophobia. ${ }^{24}$ These experiences have been extensively documented across several studies, where high prevalence of experiences of stigma and discrimination has been reported among the LGBTQ+ community. ${ }^{31}{ }^{32}$ During the pandemic, experiences of discrimination may have become magnified because, as described above, LGBTQ+ people may have been sheltering in households that were unsupportive or hostile towards their identities ${ }^{26}$ or have not received support from networks and relevant organisations. In some contexts, the pandemic has triggered a rise in hate speech and targeted attacks on the LGBTQ+ community, and members of the LGBTQ+ community have been blamed for the very emergence of the virus. ${ }^{33}$ Unrelated to the coronavirus itself, the lockdown coincided with online debates around sex and gender, which have manifested in transphobic comments made and supported by 
high-profile figures and a hostile online environment for many transgender people. ${ }^{34}$ These attacks occurred at a time when many in the community were unable to draw on their usual support networks.

In the context of the coronavirus pandemic where existent inequalities are being exacerbated across social locations, ${ }^{2}$ it is paramount to document how the LGBTQ+ community has fared during the initial stages of the coronavirus pandemic. The present study aims to address this need through analysing data from the Queerantine study (a portmanteau of queer and quarantine), a web-based survey that assesses how LGBTQ+ adults are experiencing the coronavirus pandemic. In the present paper, we examine extent to which respondents to the Queerantine survey experienced forms of sexuality or gender-based discrimination, including harassment and exclusion, during the coronavirus pandemic. We also examine how widespread experiences of perceived stress and depressive symptomology were among respondents to the Queerantine survey and examine to what extent instances of harassment and exclusion predict poorer mental health among LGBTQ+ respondents during the coronavirus pandemic.

\section{METHODS}

Data collection was conducted via a cross-sectional, webbased anonymous survey. It began on 27 April 2020 and ended on 30 December 2020. Twitter, Facebook and Instagram accounts were created for the study and were used to disseminate links to the survey in order to maximise the response rate. We contributed guest blogs and created a website in order to help publicise the study (https://queerantinestudy.wixsite.com/queerantine). The link to the survey was distributed through a number of LGBTQ+ organisations including through the newsletter of the LGBT Consortium, the largest network of LGBT+ groups, projects and organisations in the UK as well as directly by local organisations such as the East London Out Project. The target sample included respondents aged 18 and above, and who self-identify as lesbian, gay, bisexual, queer, as having another minority sexual orientation; or who were transgender or gender diverse in other ways including being nonbinary or intersex. Cisgender respondents who self-identify as heterosexual were not excluded from the survey, although recruitment and survey design were tailored towards the LGBTQ+ community, and their responses were not included in the analyses presented here. The Queerantine survey asked respondents about their sociodemographic characteristics, their physical and mental health, health behaviours and experiences and anxieties relating to the pandemic and their identity.

\section{Patient and public involvement}

Expert input from a representative of a national LGBT umbrella organisation broadened the focus of the survey to consider how respondents had experienced changes in support from LGBTQ+ service providers and organisations; this input also helped to shape the measures around gender. Community organisations also helped in the dissemination of the study through social media and inclusion of the study within newsletters. However, no further public involvement was sought in the design or analysis of the survey.

\section{Outcome variables}

In this analysis, we focus on three outcomes: depressive symptoms, perceived stress and experiences of discrimination. We assessed depression with the CES-D-10, which asks respondents to consider how much in the past week they have experienced feelings of loneliness, happiness and fear. ${ }^{35}$ The CES-D-10 includes three items on depressed affect, five items on somatic symptoms and two on positive affect. ${ }^{36}$ Scores range between 0 and 30 with good levels of internal consistency in our analytical sample (Cronbach's $\alpha=0.87$ ). Thresholds were used to denote significant depressive symptoms based on a score of 10 or more. ${ }^{35}$ In the present study, we mainly examine the CES-D-10 as a binary measure, with supplementary analyses presenting data on CES-D-10 in continuous models.

We measured stress with the PSS-4, which assesses the extent to which situations in life are viewed as stressful. ${ }^{37}$ The scale asks respondents about respondents' perceived ability to control important things in life, confidence in handling personal problems, the extent to which they felt things were going their way and whether difficulties were piling up so high they were becoming insurmountable, using the past month as a frame of reference. Scores range between 0 and 15 and have good levels of internal consistency in our analytical sample (Cronbach's $\alpha=0.83$ ).

We measured experiences of discrimination with a set of options that asked respondents whether, since the start of the coronavirus pandemic, they had experienced verbal harassment, physical harassment, sexual harassment, threats of violence, exclusion from events/activities, involuntary disclosure of LGBTQ+ identity or other forms of inappropriate treatment because they were LGBTQ+ or were perceived as being LGBTQ+. Individual measures were combined into one summary variable of 'any discrimination'.

\section{Sexual orientation and gender}

Gender was assessed using the recommended two-step method ${ }^{38}$ with two items: (1) the gender that participants felt best represented them (options included: woman (including trans woman); man (including trans man); nonbinary; other (free- text category)) and (2) whether this gender was the same as assigned at birth (options included: yes; no; do not know). The two items were crosstabulated to categorise participants as either transgender and gender diverse (TGGD) or cisgender. Sexual orientation was captured with a question that asked participants to select their sexual orientation from the following categories: bisexual; gay/lesbian; heterosexual/straight; do 
not know; prefer not to say and an other, free-text category. Using predefined response categories, respondents could only select one category, although those who identified with multiple categories (eg, queer and bisexual or man and nonbinary) could use the free-text option to state this, with respondents declaring more than one gender being categorised as transgender and gender diverse, and respondents selecting more than one sexual orientation categorised as having another nonheterosexual orientation.

We present data on sexual orientation and gender as different constructs in supplementary analyses, although the main analyses use a variable that examines the intersection of sexual orientation and gender using five categories: (1) cisgender female lesbian/gay, (2) cisgender woman with another nonheterosexual orientation (including bisexual, other, do not know and prefer not to say), (3) transgender and gender diverse, (4) cisgender male gay, (5) cisgender man with another nonheterosexual orientation (including bisexual, other, do not know and prefer not to say).

\section{Covariates}

We adjusted for variables thought to confound the association between our exposure and outcome variables. Socioeconomic status was measured through a variable that asked respondents about their subjective social status (modelled on an approach used in general population surveys, ${ }^{39}$ and how this had changed since the start of the pandemic, with categories reflecting no change, positive change and negative change.

\section{Analytical plan}

Data for the present analyses include responses collected until 13 July 2020. The analysis mainly consisted of a complete case analysis of respondents, although a dummy category of no information (missing) for the harassment variable was created for models of mental health in order to preserve sample size. Summary statistics were calculated for baseline characteristics and associations between exposure variables and outcomes were tested in unadjusted analyses using the $\chi^{2}$ test of association and ANOVA (analysis of variance) as appropriate. The modelling began with exploring selected predictors of discrimination before examining how discrimination itself predicted poorer mental health. Binary logistic regression models were constructed for harassment and high depressive symptomology; ordinary least square regression models were constructed for continuous models of perceived stress and depressive symptoms. Results for both binary and continuous specifications of CES-D-10 are discussed, with the results for the continuous specification included in supplementary analyses, as a form of sensitivity analysis. For models where discrimination is the outcome of interest, we only adjusted for sexual orientation and gender, age, ethnicity and location. For models where depressive symptomology or perceived stress are the outcomes of interest, we used the measure of discrimination as the main exposure variable and adjusted for the same covariates as above as well socioeconomic status and relationship status. A different set of controls was used between models as the potential confounders were theorised to differ slightly and due to the lower number of 'events' in the model of discrimination.

Additional analysis examining when in the pandemic harassment and discrimination occurred is also included to contextualise the discussion. Adjusted and unadjusted models are presented, and in line with suggested practice, estimates were evaluated based the exact $p$ value, the magnitude of the coefficients and the width of the confidence intervals, rather than on a single test statistics. ${ }^{40}$ We conducted all analyses in Stata V.14. ${ }^{41}$ The decision on how to present the findings across diverse identities is challenging, particularly as we combined information on sexual orientation and gender in deriving categories. Our decisions reflected considerations of the conceptual similarities/differences between groups, the numbers across groups within our sample as well as the decision to adopt an 'inclusive' or 'specific' approach ${ }^{42}$ when analysing the data based on observed differences in key variables. Some preliminary analysis (not shown) was undertaken to explore the validity of bringing different groupings together before the decision was taken to use five main categories combining sexual orientation and gender.

\section{RESULTS}

Between 27 April and 13 July, we received a total of 426 responses. Of these, 24 were excluded because they did not provide their age and 4 were excluded because they were aged under 18 . Of the remaining 398 , we were able to calculate PSS-4 and CES-D-10 scores for 325 and 324 respondents, respectively. Once we had accounted for missingness on other covariates, the analytical sample consisted of 310 respondents for models of mental health, excluding one further cisgender heterosexual respondent.

Participants identified their sexual orientation and gender in a number of different ways. The largest group identified as cisgender gay man (30.0\%); almost a quarter of the sample $(23.5 \%)$ was categorised as TGGD (of different sexual orientations); cisgender gay and lesbian women comprised $22.9 \%$ of the respondents, while cisgender women with another nonheterosexual orientation accounted for $19.4 \%$ of respondents and cisgender men with another nonheterosexual orientation accounted for $4.2 \%$ of respondents. A further breakdown of respondents' identities is available in the online supplemental file, with descriptive information on key variables. Respondents aged 18-24 accounted for less than a fifth of the sample $(15.1 \%)$, while those aged $55+$ accounted for less than a tenth of the sample $(7.1 \%)$, with a greater representation of respondents aged 25-54 years old.

Descriptively, the mean scores for PSS-4 suggested that the sample had high levels of perceived stress (mean (M): 
Table 1 Mental health, experiences of discrimination and sociodemographic characteristics of the queerantine study respondents

$\begin{array}{llllll}\begin{array}{l}\text { Cis female } \\ \text { gay/lesbian }\end{array} & \begin{array}{l}\text { Cis female } \\ \text { of another } \\ \text { nonheterosexual } \\ \text { orientation (\%) }\end{array} & \begin{array}{l}\text { Transgender } \\ \text { and gender } \\ \text { diverse (\%) }\end{array} & \begin{array}{l}\text { Cis male gay } \\ (\%)\end{array} & \begin{array}{l}\text { Cis male of another } \\ \text { nonheterosexual } \\ \text { orientation (\%) }\end{array} & \text { Total (\%) }\end{array}$

Mental health outcomes

$\begin{array}{lcccccc}\text { PSS-4 Score, } & 6.44(3.18) & 8.33(3.14) & 8.96(2.99) & 7.03(2.97) & 9.00(3.37) & 7.672(3.218) \\ \text { M(SD) } & & & & & & \\ \text { CES-D-10 } & 12.0(6.65) & 15.0(5.86) & 17.15(6.6) & 12.75(7.17) & 16.15(7.5) & 14.174(6.948) \\ \text { Score, M(SD) } & & & & & & \end{array}$

Evidence of significant depressive symptomology

\begin{tabular}{lcccccc}
$\begin{array}{l}\text { No evidence } \\
(<10)\end{array}$ & 36.62 & 18.33 & 16.44 & 38.71 & 15.38 & 28.06 \\
$\begin{array}{l}\text { Evidence of } \\
\text { significant } \\
\text { depressive } \\
\text { symptomology } \\
(\geq 10)\end{array}$ & 63.38 & 81.67 & 83.56 & 61.29 & 84.62 & 71.94 \\
\hline
\end{tabular}

Any LGBTQ+ related harassment or inappropriate incidents

\begin{tabular}{|c|c|c|c|c|c|c|}
\hline None reported & 74.65 & 81.67 & 64.38 & 87.10 & 84.62 & 77.81 \\
\hline $\begin{array}{l}\text { Harassment } \\
\text { reported }{ }^{*}\end{array}$ & 19.72 & 13.33 & 28.77 & 7.53 & 15.38 & 16.72 \\
\hline $\begin{array}{l}\text { No information } \\
\text { (missing) }\end{array}$ & 5.63 & 5.00 & 6.85 & 5.38 & 0 & 5.47 \\
\hline \multicolumn{7}{|l|}{ Age group } \\
\hline $18-24$ & 9.86 & 18.33 & 31.51 & 2.15 & 30.77 & 15.11 \\
\hline $25-34$ & 18.31 & 45.00 & 31.51 & 32.26 & 23.08 & 30.87 \\
\hline $35-44$ & 39.44 & 23.33 & 16.44 & 31.18 & 23.08 & 27.65 \\
\hline $45-54$ & 23.94 & 10.00 & 16.44 & 23.66 & 15.38 & 19.29 \\
\hline $55+$ & 8.45 & 3.33 & 4.11 & 10.75 & 7.69 & 7.07 \\
\hline \multicolumn{7}{|c|}{ Identify as ethnic minority } \\
\hline $\begin{array}{l}\text { Not an ethnic } \\
\text { minority }\end{array}$ & 87.32 & 81.67 & 90.41 & 83.87 & 76.92 & 85.53 \\
\hline Ethnic minority & 12.68 & 16.67 & 9.59 & 12.90 & 23.08 & 13.18 \\
\hline $\begin{array}{l}\text { Prefer not to } \\
\text { say }\end{array}$ & 0 & 1.67 & 0 & 3.23 & 0 & 1.29 \\
\hline \multicolumn{7}{|l|}{ Location } \\
\hline UK & 81.69 & 80.00 & 82.19 & 90.32 & 76.92 & 83.60 \\
\hline $\begin{array}{l}\text { Rest of the } \\
\text { world }\end{array}$ & 18.31 & 20.00 & 17.81 & 9.68 & 23.08 & 16.40 \\
\hline \multicolumn{7}{|c|}{ Change in perceived social status } \\
\hline $\begin{array}{l}\text { Negative } \\
\text { change in } \\
\text { status }\end{array}$ & 25.35 & 26.67 & 36.99 & 23.66 & 23.08 & 27.65 \\
\hline No change & 52.11 & 43.33 & 35.62 & 51.61 & 61.54 & 46.95 \\
\hline $\begin{array}{l}\text { Positive } \\
\text { change }\end{array}$ & 22.54 & 30.00 & 27.40 & 24.73 & 15.38 & 25.40 \\
\hline Total & & & & & & 100.00 \\
\hline \multicolumn{7}{|l|}{$\begin{array}{l}\text { Relationship } \\
\text { status }\end{array}$} \\
\hline Single & 21.13 & 25.00 & 42.47 & 19.35 & 23.08 & 26.37 \\
\hline
\end{tabular}




\begin{tabular}{|c|c|c|c|c|c|c|}
\hline & $\begin{array}{l}\text { Cis female } \\
\text { gay/lesbian } \\
(\%)\end{array}$ & $\begin{array}{l}\text { Cis female } \\
\text { of another } \\
\text { nonheterosexual } \\
\text { orientation (\%) }\end{array}$ & $\begin{array}{l}\text { Transgender } \\
\text { and gender } \\
\text { diverse }(\%)\end{array}$ & $\begin{array}{l}\text { Cis male gay } \\
(\%)\end{array}$ & $\begin{array}{l}\text { Cis male of another } \\
\text { nonheterosexual } \\
\text { orientation (\%) }\end{array}$ & Total (\%) \\
\hline $\begin{array}{l}\text { Dating or in } \\
\text { a relationship } \\
\text { but not living } \\
\text { together }\end{array}$ & 21.13 & 30.00 & 19.18 & 26.88 & 46.15 & 25.08 \\
\hline $\begin{array}{l}\text { Divorced, } \\
\text { widowed or } \\
\text { prefer not to } \\
\text { say }\end{array}$ & 1.41 & 0 & 4.11 & 4.30 & 0 & 2.57 \\
\hline
\end{tabular}

*See the Methods section for types of incidents.

CES-D-10, 10-item Center for Epidemiological Studies Depression scale ; LGBTQ, lesbian, gay, bisexual, transgender, queer; M, mean; PSS4, 4-item Perceived Stress Scale; (SD), Standard Deviation

7.67; SD: 3.22). Using the recommended threshold of 10 or more to identify significant depressive symptomatology, we observed that the majority of respondents fell into this category $(71.9 \%)$. Cis woman respondents who identify as gay or lesbian had the lowest scores for perceived stress or depressive symptoms (see table 1); conversely transgender and gender-diverse individuals had the highest scores $(83.6 \%)$.

One-in-six respondents reported some forms of harassment since the start of the pandemic because they were LGBTQ+ (16.7\%); the most common forms being verbal harassment including insults or other hurtful comments $(8.7 \%)$, exclusion from events or activities $(5.6 \%)$ and involuntary disclosure of LGBTQ+ identity (3.5\%). Perceived stress was markedly higher for those who had experienced discrimination (PSS-4 M: 9.44 SD: 2.99) compared with those who had not (PSS-4 M: 7.35 SD: 3.16). Respondents who had experienced discrimination also had higher depressive symptomology scores (CESD-10 M: 17.87 SD: 6.21) compared with those who had not (CES-D-10 M: 13.43 SD: 6.97).

We examined the relationship between gender and sexual orientation and discrimination in logistic regression models (see table 2). Based on the association observed in table 1, we used TGGD as the reference category and explored whether the higher risk of TGGD people to experience discrimination remained after controlling for basic sociodemographic covariates. The results from adjusted models showed that the odds of experiencing discrimination were lower for all other groups and significantly lower in the case of cisgender gay men (OR: $0.237,95 \%$ CI 0.091 to 0.617 ) and cisgender women who identified with a sexual minority orientation other than gay/lesbian (OR: 0.361, CI 0.141 to 0.921 ). Within the sample, the results were suggestive of a u-shaped trend in terms of age, with the youngest and the oldest LGBTQ+ respondents in the sample being at greatest risk of experiencing discrimination, although differences by age were generally not statistically significant.

Experiences of discrimination were clear predictors of poorer mental health. The average score for perceived stress increased by 1.44 points (CI: 0.517 to 2.354) for those who had experienced discrimination, compared with those who had not. Similarly, the odds of exhibiting significant depressive symptomology (CES-D-10 scores of 10 or more) increased threefold among those who had experienced discrimination based on their gender or sexuality compared with those who had not (OR: $3.251 ; 95 \%$ CI 1.168 to 9.052 ). These marked associations remained after adjusting for potential confounders (see models 1-4 in table 3 ).

Cisgender female lesbian or gay respondents had lower perceived stress levels than other LGBTQ+ groups. TGGD respondents and nonheterosexual cisgender men who did not identify as gay had among the highest average perceived stress scores in adjusted models. Although similar trends were observed in the odds of experiencing depressive symptomatology, the evidence was ultimately inconclusive for these groups, although cisgender women with another nonheterosexual orientation besides lesbian or gay had a higher risk of significant depressive symptoms relative lesbian/gay cisgender women. Further sensitivity analysis of the CES-D-10 as a continuous measure (see online supplemental file) shows that TGGD people 
Table 2 Logistic regression results for unadjusted and adjusted associations between gender identity/sexual orientation and discrimination during COVID-19 pandemic (ORs and Cls in brackets)

Experiences of discrimination

Unadjusted OR (Cl) Adjusted OR (Cl)

\begin{tabular}{lll}
$\begin{array}{l}\text { Gender ID and sex orientation baseline: transgender and } \\
\text { gender diverse }\end{array}$ & 0.743 \\
\hline Cis female gay/lesbian & 0.576 & $(0.320$ to 1.727$)$ \\
\hline $\begin{array}{l}\text { Cis female of another } \\
\text { nonheterosexual } \\
\text { orientation }\end{array}$ & $0.364^{* *}$ & $0.361^{\star *}$ \\
\hline $\begin{array}{l}\text { Cis male gay } \\
\text { Cis male of another }\end{array}$ & 0.147 to 0.897$)$ & $(0.141$ to 0.921$)$ \\
$\begin{array}{l}\text { nonheterosexual } \\
\text { orientation }\end{array}$ & 0.364 & $0.237^{* * *}$ \\
\hline
\end{tabular}

Age group baseline: 18-24years

\begin{tabular}{ll} 
25-34 years & 0.981 \\
& $(0.411$ to 2.347$)$ \\
\hline $35-44$ years & $0.302^{\star \star}$ \\
& $(0.102$ to 0.896$)$ \\
$45-54$ years & 0.409 \\
& $(0.139$ to 1.205$)$ \\
\hline $55+$ years & 1.567 \\
& $(0.474$ to 5.188$)$ \\
\hline $\begin{array}{l}\text { Ethnic minority } \\
\text { (baseline: not an ethnic } \\
\text { minority) }\end{array}$ & 1.345 \\
Location: rest of the & $(0.520$ to 3.484$)$ \\
world (baseline: UK) & 0.530 \\
Observations & $(0.204$ to 1.375$)$ \\
\hline
\end{tabular}

${ }^{\star * *} p<0.01,{ }^{* \star} p<0.05,{ }^{\star} p<0.1$

had substantially higher CES-D-10 scores than cisgender lesbian or gay women, with an average score of 3.38 points (95\% CI 1.172 to 5.595) higher after adjusting for other covariates. A clear trend by age was observed in models 3 and 4 (see table 3 ), with younger respondents having significantly poorer mental health than older individuals, both for perceived stress and significant depressive symptomology, after adjusting for other covariates.

\section{DISCUSSION}

In this study, we present data on the levels of depressive symptoms, perceived stress and experiences of discrimination of LGBTQ+ people during the COVID-19 pandemic collected through a web-based survey. Respondent characteristics broadly mirrored the sociodemographic characteristics of the recent UK government National LGBT Survey. ${ }^{43}$ The distribution of respondents by sexual orientation was very similar, although with a higher share of respondents who identified as queer in the Queerantine survey ( $8 \%$ vs approximately $1 \%$ ). The proportion of respondents aged 18-24 was lower at 15.1\% (compared with approximately $37.4 \%$ ), with higher proportions at older age groups in line with the UK population as a whole. The Queerantine survey had a larger proportion of participants who were TGGD than the UK National LGBT Survey $(23.5 \%$ vs $15 \%){ }^{43}$

We find that scores for perceived stress and depressive symptoms among our LGBTQ+ sample are high, and higher than observed in community samples and vulnerable populations in the recent past ${ }^{44}$. Furthermore, we find that the pandemic may not be impacting the LGBTQ+ community evenly, with TGGD individuals having particularly high scores for perceived stress and depressive symptoms relative to cisgender gay and lesbian individuals. Non-heterosexual respondents who are cisgender but do not identify as lesbian or gay also had elevated scores for perceived stress and depressive symptoms. Similarly, there was a clear age gradient with younger LGBTQ+ people having much higher risks of showing symptoms of stress and depression. This is in line with findings elsewhere that suggest younger people were at elevated risk of experiencing stress, anxiety and depression during the pandemic. ${ }^{46}$ An important caveat to these results is that because of our cross-sectional design, we are unable to definitively state that mental health status deteriorated as a result of the pandemic and whether any deterioration in mental health was concentrated among TGGD respondents or younger respondents; our study design also means we are unable to make direct comparisons to ascertain whether LGBTQ+ people are faring worse during the pandemic than heterosexual cisgender people. However, the underlying pathways through which LGBTQ +peoplemay have experienced greater and specific challenges during the pandemic and lockdown are becoming evident, ${ }^{22}{ }^{26-30}$ providing a basis for an assumption that LGBTQ+ people may have experienced greater stressors, with TGGD people facing particular sets of stressors, although on a theoretical basis and in need of further exploration and verification. Furthermore, the very high levels of mental health issues uncovered here make it challenging to simply attribute such stark levels of mental health issues as the status quo prepandemic, although this assumption again needs further exploration and verification using a different study design. Regardless, the data strongly suggest that the pandemic has had a pernicious effect on the mental health of the LGBTQ+ community.

Our analyses of discrimination reinforce the rationale for undertaking analyses of LGBTQ+ health and mental health, with LGBTQ+ people theorised at greater risk of health complications due to a unique set of internal and external homophobic, heteronormative and transphobic stressors. ${ }^{47}$ We found that almost one-in-six respondents reported experiencing some form of discrimination during the pandemic, with TGGD respondents again at heightened risk of experiencing discrimination relative to other LGBTQ+ groups. Our results show that 
Table 3 Results of unadjusted and adjusted OLS regression for PSS-4 score (models 1 and 2; regression coefficients and Cls in brackets) and unadjusted and adjusted logistic regression results for odds of significant depressive symptomology indicated by CES-D-10 scores $\geq 10$ (models 3 and 4 ; ORs and Cls in brackets)

\begin{tabular}{|c|c|c|c|c|}
\hline & \multicolumn{2}{|l|}{ PSS-4 score } & \multicolumn{2}{|c|}{ CES-D-10 scores $\geq 10$} \\
\hline & Unadjusted B (Cl) & Adjusted B (Cl) & Unadjusted OR (Cl) & Adjusted OR (Cl) \\
\hline \multicolumn{5}{|l|}{$\begin{array}{l}\text { Any harassment or } \\
\text { inappropriate incidents } \\
\text { baseline: none }\end{array}$} \\
\hline \multirow[t]{2}{*}{ Form of harassment reported } & $1.882^{\star \star \star}$ & $1.436^{\star \star \star}$ & $4.228^{\star \star \star}$ & $3.252^{\star *}$ \\
\hline & (0.957 to 2.807$)$ & $(0.517$ to 2.354$)$ & $(1.582$ to 11.30$)$ & (1.168 to 9.052$)$ \\
\hline \multirow[t]{2}{*}{ No information } & -0.378 & -0.756 & 2.325 & 1.796 \\
\hline & $(-1.863$ to 1.108$)$ & $(-2.198$ to 0.686$)$ & $(0.634$ to 8.520$)$ & $(0.456$ to 7.074$)$ \\
\hline \multicolumn{5}{|c|}{ Gender ID and sex orientation baseline: cis female gay/lesbian } \\
\hline \multirow{2}{*}{$\begin{array}{l}\text { Cis female of another } \\
\text { nonheterosexual orientation }\end{array}$} & $2.014^{\star \star \star}$ & $1.367^{\star \star \star}$ & $2.881^{* *}$ & $2.154^{*}$ \\
\hline & (0.977 to 3.052$)$ & (0.345 to 2.389$)$ & (1.257 to 6.604$)$ & (0.890 to 5.210$)$ \\
\hline \multirow{2}{*}{$\begin{array}{l}\text { Transgender and gender } \\
\text { diverse }\end{array}$} & $2.357^{\star \star \star}$ & $1.561^{\star \star \star}$ & $2.748^{\star \star}$ & 1.904 \\
\hline & (1.369 to 3.345$)$ & (0.570 to 2.552$)$ & (1.231 to 6.134$)$ & (0.791 to 4.580$)$ \\
\hline \multirow[t]{2}{*}{ Cis male gay } & $0.824^{*}$ & $0.769^{*}$ & 1.061 & 0.986 \\
\hline & $(-0.113$ to 1.761$)$ & $(-0.145$ to 1.683$)$ & (0.550 to 2.046$)$ & (0.487 to 1.998$)$ \\
\hline \multirow{2}{*}{$\begin{array}{l}\text { Cis male of another } \\
\text { nonheterosexual orientation }\end{array}$} & $2.624^{* * *}$ & $1.982^{\star \star}$ & 3.626 & 2.553 \\
\hline & (0.840 to 4.407$)$ & (0.255 to 3.709$)$ & (0.732 to 17.97$)$ & (0.481 to 13.56$)$ \\
\hline \multicolumn{5}{|c|}{ Age group baseline: $18-24$ years } \\
\hline \multirow[t]{2}{*}{ 25-34 years } & & $-1.070^{* *}$ & & 0.558 \\
\hline & & $(-2.127$ to -0.0125$)$ & & (0.182 to 1.713$)$ \\
\hline \multirow[t]{2}{*}{ 35-44 years } & & $-1.995^{\star \star \star}$ & & 0.480 \\
\hline & & $(-3.094$ to -0.897$)$ & & (0.157 to 1.470$)$ \\
\hline \multirow[t]{2}{*}{$45-54$ years } & & $-2.401^{\star \star \star}$ & & $0.309^{* *}$ \\
\hline & & $(-3.574$ to -1.228$)$ & & (0.098 to 0.974$)$ \\
\hline \multirow[t]{2}{*}{$55+$ years } & & $-3.384^{\star \star \star}$ & & 0.361 \\
\hline & & $(-4.907$ to -1.860$)$ & & (0.089 to 1.469$)$ \\
\hline \multicolumn{5}{|c|}{ Change in social status since pandemic baseline: positive change } \\
\hline \multirow[t]{2}{*}{ Negative change in status } & & $1.375^{\star \star \star}$ & & 1.653 \\
\hline & & $(0.478$ to 2.272$)$ & & (0.747 to 3.657$)$ \\
\hline \multirow[t]{2}{*}{ No change } & & 0.217 & & 0.882 \\
\hline & & $(-0.590$ to 1.025$)$ & & $(0.452$ to 1.719$)$ \\
\hline \multicolumn{5}{|c|}{ Relationship status baseline: single } \\
\hline \multirow{2}{*}{\multicolumn{2}{|c|}{$\begin{array}{l}\text { Dating or in a relationship but } \\
\text { not living together }\end{array}$}} & 0.225 & & 0.953 \\
\hline & & $(-0.682$ to 1.132$)$ & & (0.410 to 2.211$)$ \\
\hline \multirow{2}{*}{$\begin{array}{l}\text { Cohabiting/married/civil } \\
\text { partner }\end{array}$} & & -0.332 & & $0.499^{*}$ \\
\hline & & $(-1.159$ to 0.496$)$ & & $(0.244$ to 1.018$)$ \\
\hline \multirow{2}{*}{$\begin{array}{l}\text { Divorced, widowed or prefer } \\
\text { not to say }\end{array}$} & & -0.328 & & 0.625 \\
\hline & & $(-2.463$ to 1.806$)$ & & (0.119 to 3.282$)$ \\
\hline \multicolumn{5}{|c|}{ Ethnicity baseline: not an ethnic minority } \\
\hline \multirow[t]{2}{*}{ Ethnic minority } & & -0.378 & & 1.525 \\
\hline & & $(-1.353$ to 0.598$)$ & & (0.642 to 3.626$)$ \\
\hline \multirow[t]{2}{*}{ Prefer not to say } & & 1.621 & & 1.778 \\
\hline & & $(-1.272$ to 4.515$)$ & & (0.159 to 19.85$)$ \\
\hline
\end{tabular}


Table 3 Continued

\begin{tabular}{|c|c|c|c|c|}
\hline & \multicolumn{2}{|l|}{ PSS-4 score } & \multicolumn{2}{|l|}{ CES-D-10 scores $\geq 10$} \\
\hline & Unadjusted B (Cl) & Adjusted B (Cl) & Unadjusted OR (Cl) & Adjusted OR (Cl) \\
\hline \multirow{2}{*}{$\begin{array}{l}\text { Location: rest of the world } \\
\text { (baseline: UK) }\end{array}$} & & -0.0235 & & 1.076 \\
\hline & & (-0.916 to 0.869$)$ & & (0.496 to 2.332$)$ \\
\hline Constant & $6.087^{* * *}$ & $7.774^{\star * *}$ & & \\
\hline $\mathrm{R}^{2}$ & 0.147 & 0.263 & & \\
\hline
\end{tabular}

${ }^{\star * *} \mathrm{p}<0.01,{ }^{\star *} \mathrm{p}<0.05,{ }^{*} \mathrm{p}<0.1$; B: regression coefficient.

CES-D-10, 10-item Center for Epidemiological Studies Depression scale ; LGBTQ, lesbian, gay, bisexual, transgender, queer; OLS, ordinary least square; PSS-4, 4-item Perceived Stress Scale.

experiencing discrimination was a risk factor for higher perceived stress and depressive symptomology; the odds of reporting depressive symptomatology among individuals who had experienced discrimination were three times higher than among individuals who had not experienced any discrimination. Open-ended responses to the survey described various experiences of discrimination and inappropriate incidents including increased or excessive scrutiny, misgendering, exclusion and online abuse.

To further understand the results, we explored how mental health and discrimination varied over the course of the survey. We observed that mental health scores in the sample were poorer during the period 27 April-10 May (the moment of 'maximum risk' as defined by the UK prime minister) and during the period between 23 May and 14 June (coinciding with revelations of lockdown breaches by government officials in the UK, transphobic comments on social media made by high-profile figures and protests surrounding the murder of George Floyd), although these differences were not significant. Similarly, we observed nonstatistically significant differences in the proportion of respondents reporting instances of discrimination, with the initial easing of the lockdown and

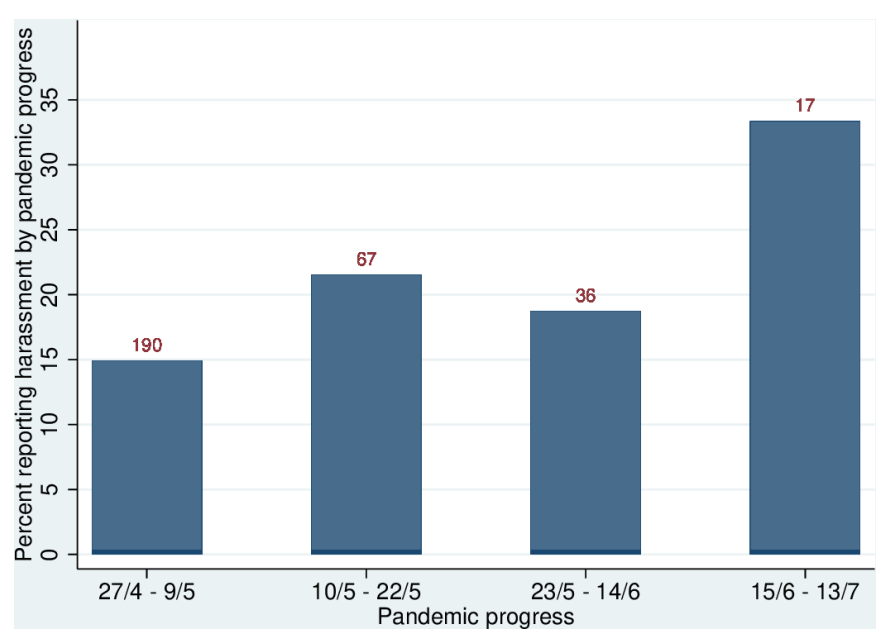

Figure 1 Proportion of respondents reporting discrimination by period in the pandemic (numbers at top of column). particularly the period from 15 June onwards coinciding with increases in discrimination (see figure 1), although based on a small sample in the latter period. These trends help contextualise the results and illuminate the hostile environments, which LGBTQ+ people, and particularly TGGD respondents, were experiencing.

\section{Limitations}

Due to relatively small sample sizes, we have not been able to fully examine the diversity of the LGBTQ+ community and fully examine how experiences vary according to social locations such as ethnicity, age and gender. Studies in the USA show that the highest levels of violence are reported among transgender women of colour, and among young and low-income transgender people, ${ }^{31} 32$ suggesting that violence on the basis of transgender identity or expression often affects the most marginalised subpopulations. Although we have adjusted for these factors in our models, we have not been able to further disaggregate across social locations to examine the role of interlocking systems of oppression in patterning experiences of discrimination and adverse mental health.

While our data collection efforts are limited by the inherent challenge of surveying a small, dispersed, diverse and difficult to reach population, it is nonetheless critically important to study the lives and experiences of discrimination and mental health among LGBTQ+ communities because of the stark health and social inequalities they experienced before the pandemic. Our choice of mental health measures reflected the need to field short scales within a web-based survey where there was no incentive provided for respondents to complete the questions. However, other more comprehensive or alternative measures of mental health, and particularly mental well-being, may have yielded further nuance to the results presented here.

New purposeful data collection was deemed appropriate as although a number of large representative studies (eg, the UK Household Longitudinal Study) are currently collecting data on COVID-19 experiences, they typically contain small numbers of LGBTQ+ people, ${ }^{812}$ often do 
not collect information on TGGD identities, and contain heteronormative measures that can be exclusionary to LGBTQ+ respondents. An online convenience sample was deemed appropriate due to the absence of robust data on LGBTQ+ people from large surveys that could help determine the characteristics of a representative sample of LGBTQ+ people, as well as the risks inherent with any form of physical data collection during the pandemic. An online approach was particularly suitable for those respondents who may have been sheltering or shielding in households where their LGBTQ+ status was unknown to other members of the household. Furthermore, this approach is in line with other recent large-scale efforts at understanding the health of LGBT people in the UK. ${ }^{43}$ We do, nevertheless, acknowledge that an online convenience sample can introduce potential issues around sample selection, such as the omission of those without internet access, and the possibility that those living in stressful situations or with depressive symptoms were more likely to self-select into the survey. Although rudimentary checks for data patterns that could indicate that 'bots' completed the survey were implemented, focused on identifying cases where the same response had been provided to all Likert scale type questions or where the middle response had been consistently provided, there remains a possibility that some responses may be based on false or duplicate records. Further measures that could have been implemented, such as password protection or identity checking, were not congruent with a format that allowed respondents to complete the survey anonymously.

As the inferential analysis consisted of three regression models where we show the development of the model by including additional regressors, we did not implement additional correction for multiple hypotheses (eg, Bonferroni). We do note that, given a scenario where 20 hypotheses were being tested at a $5 \%$ level, we would expect to see at least one such deviation where we would interpret a result as being 'statistically significant' inappropriately ${ }^{48}$; however, as discussed earlier, we also took a broader approach to evaluating estimates than interpreting $\mathrm{p}$ values as being 'significant' or 'nonsignificant'. ${ }^{40}$

\section{Public health implications}

Results from the Queerantine study suggest that groups within LGBTQ+ acronym may be at differential risk of experiencing stress or depressive symptomology, although the sample as a whole may also be at higher risk than the general population of stress and depressive symptomology due to minority stress. Homophobic and transphobic harassment and exclusion experienced during the pandemic has a deleterious impact on LGBTQ+ mental health, demonstrated by the strong and consistent associations between harassment and poorer mental health in the models. Open-ended responses to survey questions emphasise the importance of LGBTQ+ social networks, often facilitated by the work of LGBTQ+ organisations, in supporting LGBTQ+ individuals. However, these are the very organisations that are facing financial challenges with many on the brink of closure. ${ }^{49}$

Globally, LGBT+ rights organisations have alerted policymakers about the need to address the vulnerability of the LGBTQ+ community to the coronavirus pandemic, including collecting sexual orientation and gender data for COVID-19 cases, increased socioeconomic support for disadvantaged individuals and support for organisations working with the community. ${ }^{50}$ Our findings provide support to these demands given the documented high prevalence of depressive symptomology and stress and the concerning reports of experiences of discrimination. Poor LGBTQ+ mental health may remain unchecked without substantial commitment and funding directed to ameliorating health inequalities exacerbated by the pandemic.

Acknowledgements We would like to thank the participants of the Queerantine Study for sharing their experiences with us. We would also like to thank Harri Weeks and the National LGB\&T Partnership for their advice and to all those who have helped to promote the study through social media and in other ways. We would also like to thank Joanna Boyce for contributing social media expertise that helped to boost the response rate. We would like to thank the peer reviewers of this article for their comments and suggestions on an earlier draft.

Contributors DK and LB are equal contributors to this study. Both designed the Queerantine survey, developed the research focus, analysed the data and drafted and edited the manuscript. DK and LB are the guarantors for this study and gave full approval of this version to be published.

Funding The authors have not declared a specific grant for this research from any funding agency in the public, commercial or not-for-profit sectors.

Competing interests None declared.

Patient consent for publication Not required.

Ethics approval Ethical approval was obtained from the ethics board of the University of Sussex (ER/LB516/4) and University College London (REC 1335).

Provenance and peer review Not commissioned; externally peer reviewed.

Data availability statement No individual data are available. Due to the nature of this research, participants of this study did not agree for their data to be shared publicly, so supporting individual-level data is not available.

Supplemental material This content has been supplied by the author(s). It has not been vetted by BMJ Publishing Group Limited (BMJ) and may not have been peer-reviewed. Any opinions or recommendations discussed are solely those of the author(s) and are not endorsed by BMJ. BMJ disclaims all liability and responsibility arising from any reliance placed on the content. Where the content includes any translated material, BMJ does not warrant the accuracy and reliability of the translations (including but not limited to local regulations, clinical guidelines, terminology, drug names and drug dosages), and is not responsible for any error and/or omissions arising from translation and adaptation or otherwise.

Open access This is an open access article distributed in accordance with the Creative Commons Attribution Non Commercial (CC BY-NC 4.0) license, which permits others to distribute, remix, adapt, build upon this work non-commercially, and license their derivative works on different terms, provided the original work is properly cited, appropriate credit is given, any changes made indicated, and the use is non-commercial. See: http://creativecommons.org/licenses/by-nc/4.0/.

\section{ORCID iDs}

Dylan Kneale http://orcid.org/0000-0002-7016-978X

Laia Bécares http://orcid.org/0000-0002-4207-074X

\section{REFERENCES}

1 Bowleg L. We're not all in this together: on COVID-19, intersectionality, and structural inequality. Am J Public Health 2020;110:917-17. 
2 Marmot M, Allen J. COVID-19: exposing and amplifying inequalities. $J$ Epidemiol Community Health 2020;74:681-2.

3 Zeeman L, Sherriff N, Browne K, et al. A review of lesbian, gay, bisexual, trans and intersex (LGBTI) health and healthcare inequalities. Eur J Public Health 2019;29:974-80.

4 Conron KJ, Mimiaga MJ, Landers SJ. A population-based study of sexual orientation identity and gender differences in adult health. Am $J$ Public Health 2010;100:1953-60.

5 Hudson-Sharp N, Metcalf H. Inequality among lesbian, gay bisexual and transgender groups in the UK: a review of evidence. London: National Institute of Economic and Social Research, 2016.

6 Reisner SL, Poteat T, Keatley J, et al. Global health burden and needs of transgender populations: a review. Lancet 2016;388:412-36.

7 Shahab L, Brown J, Hagger-Johnson G, et al. Sexual orientation identity and tobacco and hazardous alcohol use: findings from a cross-sectional English population survey. BMJ Open 2017;7:e015058.

8 Bécares L. Health and socio-economic inequalities by sexual orientation among older women in the United Kingdom: findings from the UK household longitudinal study. Ageing Soc 2020;42:1-19.

9 Semlyen J, Curtis T, Varney J. Sexual orientation identity in relation to unhealthy body mass index (BMI): individual participant metaanalysis of 93,429 individuals from 12 UK health surveys. Journal of Public Health 2019:fdy224.

10 Herbst JH, Jacobs ED, Finlayson TJ, et al. Estimating HIV prevalence and risk behaviors of transgender persons in the United States: a systematic review. AIDS Behav 2008;12:1-17.

11 Fredriksen-Goldsen KI, Kim H-J, Bryan AEB, et al. The cascading effects of marginalization and pathways of resilience in attaining good health among LGBT older adults. Gerontologist 2017;57:S72-83.

12 Kneale D, Thomas J, French R. Inequalities in health and care among Lesbian, gay, and bisexual people aged 50 and older in the United Kingdom: a systematic review and meta-analysis of sources of individual participant data. J Gerontol B Psychol Sci Soc Sci 2020;75:1758-71.

13 Russell ST, Fish JN. Mental health in lesbian, gay, bisexual, and transgender (LGBT) youth. Annu Rev Clin Psychol 2016;12:465-87.

14 Schauer GL, Berg CJ, Bryant LO. Sex differences in psychosocial correlates of concurrent substance use among heterosexual, homosexual and bisexual college students. Am J Drug Alcohol Abuse 2013;39:252-8.

15 Mereish EH, Sheskier M, Hawthorne DJ, et al. Sexual orientation disparities in mental health and substance use among black American young people in the USA: effects of cyber and bias-based victimisation. Cult Health Sex 2019;21:985-98.

16 Jia R, Ayling K, Chalder T. Mental health in the UK during the COVID-19 pandemic: early observations. MedRxiv2020.

17 Malik AO, Gosch K, et al, Poghni Peri-Okonny. Association of perceived stress with health status outcomes in patients with peripheral artery disease. J Psychosom Res 2021;140:110313.

18 Rosenberg M, Luetke M, Hensel D, et al. Depression and loneliness during April 2020 COVID-19 restrictions in the United States, and their associations with frequency of social and sexual connections. Soc Psychiatry Psychiatr Epidemiol 2021. doi:10.1007/s00127-02002002-8. [Epub ahead of print: 02 Jan 2021].

19 Davidson M. Seeking refuge under the umbrella: inclusion, exclusion, and organizing within the category transgender. Sex Res Soc Policy 2007;4:60-80.

20 Meyer IH, Brown TNT, Herman JL, et al. Demographic characteristics and health status of transgender adults in select us regions: behavioral risk factor surveillance system, 2014. Am J Public Health 2017:107:582-9.

21 Marmet S, Wicki M, Gmel G. Sexual minority orientation is associated with greater psychological impact due to the COVID-19 crisis-evidence from a longitudinal cohort study of young Swiss men. PsyArXiv2021;15.

22 Linnemayr S, Barreras JL, Izenberg M, et al. Longitudinal assessment of changes in mental and sexual health outcomes due to COVID-19 among Latinx SMM and TGW. J Acquir Immune Defic Syndr 2020;85:e90-2.

23 Rodriguez-Seijas C, Fields EC, Bottary R, et al. Comparing the impact of CoViD-19-related social distancing on mood and psychiatric indicators in sexual and gender minority (Sgm) and nonSGM individuals. Front Psychiatry 2020;11:590318.

24 Hendricks ML, Testa RJ. A conceptual framework for clinical work with transgender and gender nonconforming clients: an adaptation of the minority stress model. Prof Psychol 2012;43:460-7.
25 Meyer IH. Prejudice, social stress, and mental health in lesbian, gay, and bisexual populations: conceptual issues and research evidence. Psychol Bull 2003;129:674-97.

26 Gonzales G, Loret de Mola E, Gavulic KA, et al. Mental health needs among lesbian, gay, bisexual, and transgender college students during the COVID-19 pandemic. J Adolesc Health 2020;67:645-8.

27 Gato J, Barrientos J, Tasker F, et al. Psychosocial effects of the COVID-19 pandemic and mental health among LGBTQ+ young adults: a cross-cultural comparison across six nations. $J$ Homosex 2021:68:612-30.

28 Thomas B. Only connect - the impact of Covid-19 on older LGBT+ people. London: Opening Doors London, 2020.

29 Jarrett BA, Peitzmeier SM, Restar A, et al. Gender-affirming care, mental health, and economic stability in the time of COVID-19: a global cross-sectional study of transgender and non-binary people. medRxiv 2020. doi:10.1101/2020.11.02.20224709. [Epub ahead of print: 04 Nov 2020].

30 Koehler A, Motmans J, Alvarez LM. How the COVID-19 pandemic affects transgender health care in upper-middle-income and highincome countries-A worldwide cross-sectional survey 2020.

31 Bradford J, Reisner SL, Honnold JA, et al. Experiences of transgender-related discrimination and implications for health: results from the Virginia transgender health Initiative study. Am J Public Health 2013;103:1820-9.

32 White Hughto JM, Reisner SL, Pachankis JE. Transgender stigma and health: a critical review of stigma determinants, mechanisms, and interventions. Soc Sci Med 2015;147:222-31.

33 Gahan L, Almack K. Experiences of and responses to disempowerment, violence, and injustice within the relational lives of lesbian, gay, bisexual, transgender, and queer people. Journal of Sociology 2020;56:507-15.

34 Tudor A. Terfism is white distraction: on BLM, Decolonising the curriculum, Anti-Gender attacks and feminist Transphobia. Engenderings. London: LSE, 2020.

35 Andresen EM, Malmgren JA, Carter WB, et al. Screening for depression in well older adults: evaluation of a short form of the CES-D. Am J Prev Med 1994:10:77-84.

36 Baron EC, Davies T, Lund C. Validation of the 10-item centre for epidemiological studies depression scale (CES-D-10) in Zulu, Xhosa and Afrikaans populations in South Africa. BMC Psychiatry 2017;17:6.

37 Cohen S, Kamarck T, Mermelstein R. A global measure of perceived stress. J Health Soc Behav 1983;24:385-96.

38 The GenIUSS Group. Best practices for asking questions to identify transgender and other gender minority Respondents on population-based surveys. Los Angeles, CA: The Williams Institute, 2014.

39 Singh-Manoux A, Adler NE, Marmot MG. Subjective social status: its determinants and its association with measures of ill-health in the Whitehall II study. Soc Sci Med 2003;56:1321-33.

40 Greenland S, Senn SJ, Rothman KJ, et al. Statistical tests, P values, confidence intervals, and power: a guide to misinterpretations. Eur $J$ Epidemiol 2016;31:337-50.

41 StataCorp LP. Stata Statistical Software: Release 14 [program. College Station, TX, 2015.

42 Restar A, Jin H, Operario D. Gender-inclusive and gender-specific approaches in trans health research. Transgend Health 2020.

43 Government Equalities Office. National LGBT survey. Manchester: Government Equalities Office, 2018.

44 Warttig SL, Forshaw MJ, South J, et al. New, normative, Englishsample data for the short form perceived stress scale (PSS-4). $J$ Health Psychol 2013;18:1617-28.

45 Zhang W, O'Brien N, Forrest JI, et al. Validating a shortened depression scale (10 item CES-D) among HIV-positive people in British Columbia, Canada. PLoS One 2012;7:e40793.

46 Varma $\mathrm{P}$, Junge $\mathrm{M}$, Meaklim $\mathrm{H}$, et al. Younger people are more vulnerable to stress, anxiety and depression during COVID-19 pandemic: a global cross-sectional survey. Prog Neuropsychopharmacol Biol Psychiatry 2021;109:110236.

47 Frost DM, Lehavot K, Meyer IH. Minority stress and physical health among sexual minority individuals. J Behav Med 2015;38:1-8.

48 Gelman A, Hill J, Yajima M. Why we (usually) don't have to worry about multiple comparisons. J Res Educ Eff 2012;5:189-211.

49 LGBT Consortium. The impact of COVID-19 on LGBT+ service delivery. London: LGBT Consortium, 2020.

50 National LGBT Cancer Network. Open Letter about Coronavirus and the LGBTQ+ Communities. Over 100 Organizations Ask Media \& Health Officials to Weigh Added Risk. New York, NY: Network TNLC, 2020. 